удк 339.92

\title{
В.А. Сокуренко
}

Владивостокский государственный университет экономики и сервиса Владивосток. Россия

\section{Динамика и структурный анализ привлечения инвестиций КНР в экономику Дальнего Востока}

\begin{abstract}
В контексте экономического, культурного и политического взаимодействия Китая и России инвестиционное сотрудничество является одним из приоритетных направлений. С начала 2000-х годов Китай добился существенных успехов в сфере экспорта капитала. На сегодняшний день китайские инвестиции присутствуют во всех регионах мира и представлены во всех отраслях. За период 2014-2018 гг. Россия заняла 12 место в мире по объемам полученных китайских инвестиций. В статье представлено исследование динамики и структуры китайских инвестиций в экономику Дальнего Востока. Установлено, что инвестиционное сотрудничество России и Китая является приоритетом развития двухстороннего экономического сотрудничества, поскольку отвечает интересам обеих стран. Особое внимание в качестве участника инвестиционного сотрудничества уделяется российскому Дальнему Востоку в силу трансграничного положения и, как следствие, устоявшихся культурных связей. Активизация инвестиционного сотрудничества связана с созданием особых экономических зон в Дальневосточном федеральном округе - территории опережающего развития (ТОР) и свободный порт Владивосток. Определено, что наибольший интерес для китайских инвесторов в регионе представляют такие отрасли, как деревообработка, добыча металлических руд и нерудных полезных ископаемых, сельское хозяйство и животноводство. Утверждается, что при создании определенных условий китайские инвестиции могут стать драйвером экономического развития российского Дальнего Востока и важнейшей предпосылкой реализации установленных на государственном уровне целей по развитию экономики данного региона. На основе проведенных исследований выявлены и систематизированы проблемы, в значительной степени тормозящие инвестиционный поток: относительно не развитая инфраструктура, бюрократия, административная неэффективность, а также незначительный внутренний спрос.
\end{abstract}

Ключевые слова и словосочетания: Россия, Китай, динамика, структурный анализ, экспорт капитала, инвестиционное сотрудничество, Дальний Восток.

Сокуренко Валерия Андреевна - ассистент кафедры международного маркетинга и торговли; e-mail: valeria2003@list.ru 


\title{
V.A. Sokurenko
}

Vladivostok State University of Economics and Service

Vladivostok. Russia

\section{Dynamic and Structural Analysis of Encouragement of Chinese Investment in the Russian Far East Economy}

\begin{abstract}
In the context of economic and politic cooperation between Russia and China, the investment cooperation is one of the most priority sphere. Since 2000 China has been succeeding in capital export. Currently Chinese make investments in all economic sectors all over the world. During the period 2014-2018 years, Russia took a 12 position in the world according to the volume of received Chinese investments. The analysis of structure and dynamic of Chinese investment in the Russian Far East economy is presented in the article. It is determined that investment cooperation between Russia and China is a bilateral economic cooperation development priority as it is important for both sides. Because of trans frontier position and established cultural connections, the Russian Far East as a participant of investment cooperation is given a priority. One of the reason of investment cooperation activation is establishing of special economic zones in the Far Eastern Federal District - advanced special economic zones and Free Port of Vladivostok. It is settled that Chinese investors are interested in following regional economic sectors: woodworking, extraction of metallic and non-metallic mineral resources, agriculture and animal industry. It is confirmed that Chinese investment may become a driver of the Russian Far East economic development and also may become a reason for pursuing a goal of region economic development, settled by the government. The problems that slowing the investment process were determined and systematized. They are rather poor infrastructure, formalism, administrational inefficiency and small domestic demand.
\end{abstract}

Keywords: Russia, China, dynamic, structural analysis, capital export, investment cooperation, the Far East.

В последние годы в научном мире активно обсуждается проблема привлечения инвестиций. Иностранный капитал играет важную роль в развитии национальной экономики: активизация инвестиционного процесса способствует внедрению современных технологий, использованию зарубежного опыта, улучшению инвестиционного климата в стране, а также развитию экономического потенциала территорий. Зачастую зарубежные инвестиции выступают в качестве стимула для выхода из кризисного состояния и начального подъема экономики.

На протяжении длительного периода между Россией и Китаем складываются тесные экономические и политические отношения, демонстрирующие хорошие перспективы для дальнейшего взаимовыгодного партнерства. Активному сближению способствуют тесные контакты на уровне руководителей государств - за последние годы председатель КНР Си Цзиньпин и президент России Владимир Путин провели около 30 встреч, которые задают направление развитию двухсторонних отношений. Стратегическое партнерство между Россией и Китаем касается образования, социальной сферы, научных изысканий. 
Значительные успехи достигнуты в экономической сфере, о чем свидетельствует рост российско-китайского товарооборота, а также активное развитие инвестиционных отношений.

Целью данного исследования является анализ динамики и структуры китайских инвестиций в экономику Дальнего Востока России.

Будучи развивающейся страной, Китай долгое время оставался получателем иностранных инвестиций. Однако по мере развития стратегии «выхода вовне», реализуемой в КНР с начала 2000-х годов, происходил рост экспорта китайского капитала. В результате за период с 2002 по 2016 год по предварительным оценкам экспорт китайского капитала вырос в 72,7 раз - с 2,7 до 196,2 млрд долларов (рис. 1) [3].

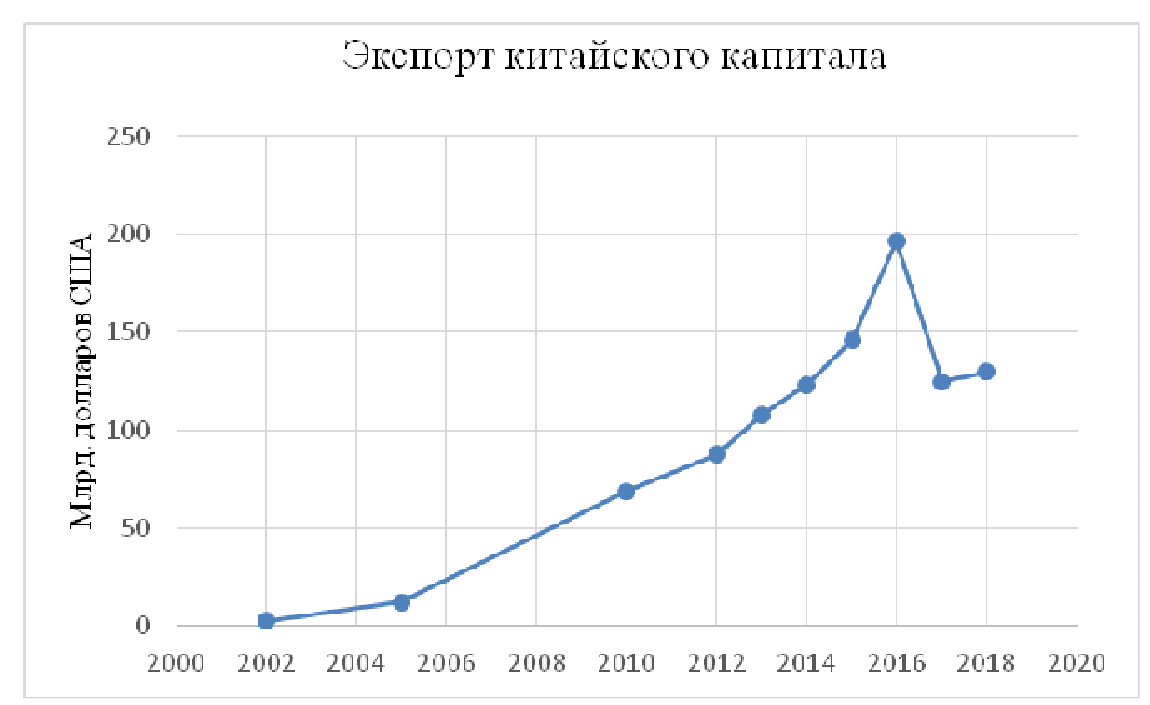

Источник: составлено автором по [3].

Рис. 1. Динамика экспорта китайского капитала

Максимального значения уровень экспорта китайского капитала достиг в 2016 году, что, с одной стороны, связано с развитием запущенного в 2013 году проекта «Один пояс - один путь», а с другой - с выводом капиталов из страны в условиях жесткой антикоррупционной кампании, инициированной руководством КНР. В 2017 году произошло значительное сокращение объемов китайских инвестиций, что объясняется рядом причин: общемировое замедление экспорта и импорта капитала, инвестиционный протекционизм Запада (в первую очередь США), а также ужесточение контроля за вывозом капитала внутри Китая. Дальнейший прирост экспорта китайского капитала был достаточно скромным.

Сфера интересов китайских инвесторов претерпевает постоянные изменения. На начальном этапе их, главным образом, интересовала добывающая отрасль, однако по мере роста зарубежных капиталовложений стали осваиваться такие сферы, как недвижимость, финансы, туризм, индустрия развлечений и здравоохранение. 
На сегодняшний день китайские инвестиции присутствуют во всех регионах мира и представлены во всех отраслях. При этом огромное влияние на географическую и отраслевую структуру экспорта капитала оказывает руководство страны, действующее в соответствии с государственными интересами [4].

По данным Американского института предпринимательства, в период 20142018 гг. Россия находилась на 12 месте в мире по объемам полученных китайских инвестиций - порядка 24 млрд долларов (табл. 1) [3].

Таблиия 1

Основные страны-получатели китайских инвестиций за период 2014-2018 гг.

\begin{tabular}{|c|l|c|}
\hline $\begin{array}{c}|c| \\
\text { № } \\
\text { п/п }\end{array}$ & \multicolumn{1}{|c|}{ Страна } & Млрд долларов США \\
\hline 1 & США & 623 \\
\hline 2 & Великобритания & 53 \\
\hline 3 & Швейцария & 46 \\
\hline 4 & Австралия & 40 \\
\hline 5 & Пакистан & 36 \\
\hline 6 & Германия & 34 \\
\hline 7 & Бразилия & 31 \\
\hline 8 & Нигерия & 30 \\
\hline 9 & Малайзия & 28 \\
\hline 10 & Сингапур & 26 \\
\hline 11 & Индонезия & 24 \\
\hline 12 & Россия & 23 \\
\hline 13 & Бангладеш & 21 \\
\hline 14 & ОАЭ & 21 \\
\hline 15 & Италия & \\
\hline & & \\
\hline
\end{tabular}

Источник: составлено автором по [7].

Можно сделать вывод, что, несмотря на тесные трансграничные связи, российская экономика недостаточно привлекательна для китайских инвесторов. При условии активной протекционистской инвестиционной политики США в указанный период на них пришлось порядка 123 млрд долларов, что в 5 раз превышает российский показатель. Китайские предприниматели связывают это с наличием значительных рисков для инвестиционной деятельности в России, к которым относятся отсутствие экономической стабильности, непрозрачность правил ведения бизнеса, коррупционная и бюрократическая составляющая эко22 
номики. Помимо этого дополнительные трудности создают недостаточная развитость кредитной системы, низкий уровень рентабельности в отдельных сфеpax, а также нехватка квалифицированных кадров [5].

Однако в последние годы наметилась тенденция роста китайских инвестиций в российскую экономику. Активное сближение двух стран на самом высоком уровне, а также совместные государственные инициативы побудили китайских инвесторов рассмотреть российский рынок в качестве потенциального объекта капиталовложений.

Особое внимание в качестве участника инвестиционного сотрудничества уделяется российскому Дальнему Востоку в силу трансграничного положения и, как следствие, устоявшихся культурных связей. Несмотря на наличие протяженной общей границы, долгое времени представители КНР не очень активно инвестировали в экономику региона. Осознавая данную ситуацию в последние 10 лет, правительство РФ предпринимает усилия по улучшению климата для китайских инвесторов.

В рамках институциональных мер в июне 2017 года Агентство Дальнего Востока по привлечению инвестиций и Китайская ассоциация по развитию предпринимательства за рубежом подписали соглашение о создании Центра привлечения и поддержки инвестиций на Дальнем Востоке. Целью создания данного института являются содействие привлечению прямых китайских инвестиций на Дальний Восток, а также поддержка китайских предпринимателей в регионе. Предполагается, что Центр должен работать на повышение информированности китайских предпринимателей о возможностях и инвестиционном потенциале Дальнего Востока России. Очевидно, что активизация инвестиционного сотрудничества с Китаем является приоритетом развития двухстороннего экономического сотрудничества.

В контексте концепции приоритетного развития на территории российского Дальнего Востока были созданы особые экономические зоны - территории опережающего развития (ТОР) и свободный порт Владивосток. Данный преференциальный режим призван увеличить приток инвестиций в национальную экономику и создать условия для образования новых производств и предприятий. По данным Американского института предпринимательства (American Enterprise Institute), за период с 2014 по 2018 год объем китайских инвестиций в российскую экономику составил 26,34 млрд долларов США [7].

К отраслям, представляющим интерес для китайских инвесторов, можно отнести деревообработку, добычу металлических руд и нерудных полезных ископаемых, сельское хозяйство и животноводство.

По данным Агентства международного сотрудничества Приморского края, на начало 2020 года участие в инвестиционных проектах на территории Приморского края приняли 46 китайских компаний, а суммарный объем инвестиций составил 35 073,3 млн рублей. Отраслевая структура китайских инвестиций в регионе представлена в табл. 2. 


\section{Отраслевая структура китайских инвестиций в экономику Приморского края}

\begin{tabular}{|l|c|c|}
\hline \multicolumn{1}{|c|}{ Отрасль } & Млн руб. & Доля, \% \\
\hline Пищевая промышленность & 10259,1 & 29,3 \\
\hline Строительство & 9321,7 & 26,6 \\
\hline Логистика и транспорт & 4382,8 & 12,5 \\
\hline Обрабатывающая промышленность & 2849,2 & 8,1 \\
\hline Добыча полезных ископаемых & 2627,0 & 7,5 \\
\hline Сфера услуг & 2396,4 & 6,8 \\
\hline Обрабатывающее производство & 1551,2 & 4,4 \\
\hline Сельское хозяйство & 1048,6 & 3,0 \\
\hline Рыбоводство и аквакультура & 501,7 & 1,4 \\
\hline Прочее & 100,5 & 0,3 \\
\hline Автомобильная промышленность & 28,0 & 0,08 \\
\hline Недвижимость и девелопмент & 7,2 & 0,02 \\
\hline
\end{tabular}

Примечание: составлено автором по данным Агентства международного сотрудничества Приморского края.

Наибольший интерес для китайских инвесторов в Приморском крае представляет пищевая промышленность - на нее приходится порядка $29 \%$ всех капиталовложений (10 259,08 млн рублей). На втором месте - строительство $(26,6 \%)$, а на третьем - логистика и транспорт (12,5\%).

Перспективным направлением для китайских инвестиций на Дальнем Востоке является сельское хозяйство. В приграничных к российским территориям районах наблюдается нехватка пахотных земель. С другой стороны, в силу схожих климатических условий возможно создание совместных фермерских хозяйств с использованием китайской сельскохозяйственной техники и трудовых ресурсов [1].

Так, в Уссурийске «Корпорация Прим Хуньчунь» реализует проект по созданию комплекса по переработке и хранению рыбной и морской продукции, а также переработке овощей. Кроме того, корпорацией была создана фермапитомник по выращиванию дальневосточной лягушки. Для этого в районе села Красный Яр была подготовлена сеть озер со специальными условиями. В Китае дальневосточная лягушка пользуется спросом, данный вид является чувствительным к чистоте окружающей среды, поэтому не только употребляется в пищу, но и применяется в медицине, косметологии. Осенью 2017 года первая партия этого товара была экспортирована в Китай.

В конце 2019 года китайская компания Country Garden Group заявила о намерении инвестировать до 3,5 млрд рублей в проект по созданию крупного сель- 
скохозяйственного предприятия на территории Еврейской автономной области. Речь идет о выращивании и глубокой переработке соевых бобов и других сельскохозяйственных культур, что позволит удвоить экспорт сои из Дальнего Востока в Китай. При этом отмечается, что одна из целей, стоящих перед компанией, заключается в создании экологически чистого продукта посредством бережного использования арендованной земли.

Интересует китайских инвесторов и строительная сфера: в амурской ТОР «Белогорск» был введен в эксплуатацию завод по производству цемента из клинкера. В июле 2019 года китайской компанией «Жуньда» в Уссурийске был запущен завод по производству древесных плит. В качестве основного материала предусматривается использование технического сырья, поставляемого из региональных лесных хозяйств: низкосортная древесина, кряжи и т.д. Продукция данного предприятия также нацелена на внутренний дальневосточный рынок, поскольку на сегодняшний день ее основная доля импортируется из Китая. Предполагается, что после полного запуска производства штат сотрудников составит порядка 167 человек.

Весомым получателем китайских инвестиций является отрасль добычи полезных ископаемых. В Красночикойском районе Забайкальского края осуществляется совместная русско-китайская разработка Зашуланского каменноугольного месторождения, проектная мощность которого составляет 1,0 млн тонн угля в год. В качестве инвестора проекта выступает китайская корпорация Shenhua Group [2].

Если рассматривать географическую структуру китайских инвестиций в Приморском крае, то порядка 50\% приходится на город Владивосток, на втором месте - Надеждинский район, далее - Хасанский район, Артемовский городской округ и т.д. (рис. 2).

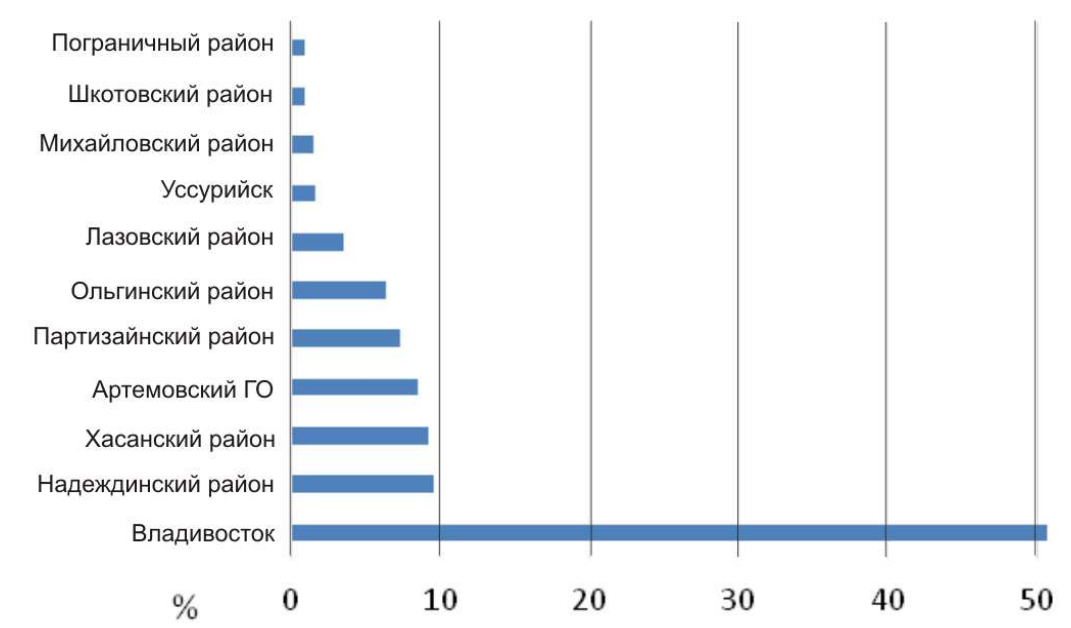

Источник: составлено автором по данным Агентства международного сотрудничества Приморского края.

Рис. 2. Географическая структура китайских инвестиций в Приморском крае 
Таким образом, будучи столицей Дальнего Востока, Владивосток является финансовым центром региона и, как следствие, точкой притяжения иностранных инвестиций. Кроме того, немаловажную роль играет и преференциальный режим «Свободный порт Владивосток».

Приход китайских инвесторов и создание новых предприятий позитивно сказываются на экономической и социальной составляющей Дальнего Востока. Это связано с появлением новых рабочих мест, развитием инфраструктуры, расширением внутреннего рынка, развитием регионов.

Увеличение потока китайских инвестиций в экономику Дальнего Востока способствует повышению интереса туристов из Поднебесной к региону: в 2018 году Приморский край посетило порядка 780 тысяч иностранных гостей, что на 20\% превысило показатель 2017 года. Из них около 422 тысяч человек граждане Китайской Народной Республики [6].

Увеличение спроса на туристические услуги дает возможность к развитию отрасли, повышению качества сервиса и услуг, продвижению «туристического бренда» региона. Дальний Восток становится востребованным среди путешественников, регион привлекает все большее количество туристов из разных концов мира.

В результате происходит активное развитие туристического бизнеса: появляются новые компании и предприятия, строятся гостиницы, возникают дополнительные рабочие места. В частности, появление нашумевшего проекта строительства аквапарка на острове Русском стало возможным лишь благодаря увеличению туристического потока, в том числе за счет туристов из Китая. Заметно и преображение центральных улиц - «визитных карточек» крупных городов: развивается инфраструктура, реставрируются исторические комплексы.

На сегодняшний день между Россией и Китаем сложились тесные взаимоотношения в разных областях - культурной, образовательной, научнотехнической, торговой и инвестиционной. Здоровое развитие двухсторонних отношений позитивно сказывается на экономике Дальнего Востока. Благодаря географическим особенностям региона устанавливаются прочные связи с приграничными провинциями Китая, в частности, Владивосток имеет статус побратима с китайскими городами Далянь, Харбин, а также Корейским автономным округом Яньбянь.

Несмотря на то, что Китай выступает основным инвестором в Дальневосточный регион, зачастую его деятельность подвергается критике. В отличие от японских предпринимателей, вкладывающих деньги в развитие технологичных сфер экономики, для китайских инвесторов больший интерес представляют области, связанные с добычей и эксплуатацией естественных природных ресурсов.

Тем не менее, развитие двустороннего сотрудничества в инвестиционной сфере отвечает интересам обеих стран. Китайские инвестиции могут стать драйвером экономического развития российского Дальнего Востока, а деловое и стратегическое сотрудничество с Китаем способствует реализации установленных на государственном уровне целей по развитию экономики Дальнего Востока. В то же время в региональной экономике наблюдается ряд проблем, в значи- 
тельной степени тормозящих инвестиционный поток, среди которых относительно не развитая инфраструктура, бюрократия, административная неэффективность, а также незначительный внутренний спрос. Реализация намеченных проектов поможет улучшить инвестиционный климат, а также поднять имидж региона на международном рынке.

По прогнозам, в 2020 году ожидается спад китайского инвестиционного потока в дальневосточную экономику. Последствия пандемии в виде сворачивания производств и закрытия государственных границ в конечном итоге приведут к замедлению проектов и снижению инвестиционной динамики.

1. Александрова М.В. О международном сотрудничестве России и Китая // Китайская Народная Республика: политика, экономика, культура 2017-2018. - Москва: Форум, 2018. - С. 257-267.

2. Беликова К.М. Дальний Восток в инвестиционных отношениях России и Китая: современное состояние и перспективы (политико-правовой аспект) // Право и политика. - 2019. - № 2. - С. 22-29.

3. Катасонов В.Ю. Об экспорте китайского капитала. - Текст: электронный // Фонд стратегической культуры: [сайт]. - URL: https:/www.fondsk.ru/news/2019/04/01/obeksporte-kitajskogo-kapitala-47906.html (дата обращения: 05.05.2020).

4. Комиссина И.Н. Новые направления инвестиционной активности Китая за рубежом и перспективы их развития // Проблемы национальной стратегии. - 2018. - №5(50). C. $155-171$.

5. Николаев А.М. Инвестиционная привлекательность России для китайских предпринимателей: обзор китайских аналитических материалов // Таможенная политика России на Дальнем Востоке. - 2018. - № 2(83). - С. 86-92.

6. Рекордное число иностранных туристов посетили Приморье в 2018 году. - Текст: электронный // Администрация Приморского края: [сайт].- URL: https://www.primorsky.ru/news/156246/ (дата обращения: 05.05.2020).

7. China global investment tracker // American Enterprise Institute.- URL: https://www.aei.org/china-global-investment-tracker/ (accessed: 05.05.2020).

\section{Транслитерация}

1. Aleksandrova M.V. O mezhdunarodnom sotrudnichestve Rossii i Kitaya // Kitajskaya Narodnaya Respublika: politika, ekonomika, kul'tura 2017-2018. - Moskva: Forum, 2018. - S. 257-267.

2. Belikova K.M. Dal'nij Vostok v investicionnyh otnosheniyah Rossii i Kitaya: sovremennoe sostoyanie i perspektivy (politiko-pravovoj aspekt) // Pravo i politika. - 2019. - № 2. S. 22-29.

3. Katasonov V.YU. Ob eksporte kitajskogo kapitala. - Tekst: elektronnyj // Fond strategicheskoj kul'tury: [sajt]. - URL: https://www.fondsk.ru/news/2019/04/01/ob-eksportekitajskogo-kapitala-47906.html (data obrashcheniya: 05.05.2020).

4. Komissina I.N. Novye napravleniya investicionnoj aktivnosti Kitaya za rubezhom i perspektivy ih razvitiya // Problemy nacional'noj strategii. - 2018. - №5(50). - S. 155-171.

5. Nikolaev A.M. Investicionnaya privlekatel'nost' Rossii dlya kitajskih predprinimatelej: obzor kitajskih analiticheskih materialov // Tamozhennaya politika Rossii na Dal'nem Vostoke. - 2018. - № 2(83). - S. 86-92. 
6. Rekordnoe chislo inostrannyh turistov posetili Primor'e v 2018 godu. - Tekst: elektronnyj // Administraciya Primorskogo kraya: [sajt]. - URL: https://www.primorsky.ru/news/156246/ (data obrashcheniya: 05.05.2020).

(C) В. А. Сокуренко, 2020

Для цитирования: Сокуренко В.А. Динамика и структурный анализ привлечения инвестиций КНР в экономику Дальнего Востока // Территория новых возможностей. Вестник Владивостокского государственного университета экономики и сервиса. - 2020. - Т. 12, № 2. - C. 19-28.

For citation: Sokurenko V.A. Dynamic and Structural Analysis of Encouragement of Chinese Investment in the Russian Far East Economy, The Territory of New Opportunities. The Herald of Vladivostok State University of Economics and Service, 2020, Vol. 12, № 2, pp. 19-28.

DOI dx.doi.org/10.24866/VVSU/2073-3984/2020-2/019-028

Дата поступления: 20.05.2020. 